\title{
ARGUMENTOS DE OPOSIÇÃO AO CRISTIANISMO NO JAPÃO DO SÉCULO XVII - OS CASOS DE FABIAN FUKAN E CRISTÓVÃO FERREIRA ${ }^{12}$ ARGUMENTS OF OPPOSITION TO CHRISTIANITY IN XVII CENTURY JAPAN - THE CASES OF FABIAN FUKAN AND CRISTÓVÃO FERREIRA
}

Miguel Carvalho Abrantes ${ }^{3}$

Resumo: Através das obras Deus Destruído e A Decepção Revelada, respectivamente da autoria de Fabian Fukan e Cristóvão Ferreira, este artigo procurará apresentar a oposição ao Cristianismo no Japão do século XVII, com vista a traçar os vectores de oposição patentes nas obras destes dois autores.

Palavras-Chave: Fabian Fukan, Cristóvão Ferreira, Século cristão japonês, Jesuítas, Oposição ao Cristianismo.

Abstract: Through the works Deus Destroyed and The Deception Revealed, respectively authored by Fabian Fukan and Cristóvão Ferreira, this article will seek to present the opposition to Christianity in Japan's XVII century, with the goal of tracing the vectors of opposition present in the works of these two authors.

Keywords: Fabian Fukan, Cristóvão Ferreira, Japanese Christian century, Jesuits, Opposition to Christianity.

1 Artigo submetido em 11/08/2018 e aprovado em 14/11/2018.

2 Um agradecimento aos Professores Margarida Miranda, José Pinto dos Santos, e ao peer anónimo pelas suas opiniões relativas a uma versão preliminar deste artigo.

3 Doutorando e Investigador no Centro de Estudos Clássicos e Humanísticos, da Faculdade de Letras, Coimbra, Portugal; miguel.r.abrantes@gmail.com (ORCID iD: http://orcid. org/0000-0003-2098-3318). 


\section{Introdução}

Fabian Fukan nasceu provavelmente no ano de 1565 no Japão (ELISON 1988: 155, HUMBERTCLAUDE 1938: 516), tendo-se associado aos Jesuítas no ano de 1586 (ELISON 1988: 145, HUMBERTCLAUDE 1938: 516), sendo possível que tenha tido alguma formação religiosa budista (HIBBARD 1962: 123124). Cristóvão Ferreira, que um dia viria também a ser conhecido como Sawano Chuan, nasceu por volta de 1580 na Zibreira (LEITÃO 1998: 291), Torres Vedras, em Portugal, entrando para a Companhia de Jesus em finais de Dezembro de 1596 (CIESLIK 1974: 1, ELISON 1988: 187-188, LEITÃO 1998: 291). Poderíamos apontar as maiores divergências entre os percursos de vida das duas figuras, mas esta breve referência que lhes fazemos passa essencialmente pelo grande elemento que têm em comum - num dado momento da sua vida ambos entraram para a mesma ordem religiosa católica, tornando-se apóstatas alguns anos mais tarde. Parece-nos bastante difícil que se tenham conhecido ${ }^{4}$, mas quando aprenderam os fundamentos da religião que os unia tiveram acesso a um conjunto de informações que, na sua posterior refutação dos preceitos do Cristianismo, poderiam vir a usar. Faria, por isso, sentido que as suas refutações da religião cristã, presentes nas obras Deus Destruído e A Decepção Revelada, tivessem vectores comuns. Mas até que ponto essa semelhança se verifica na prática? Ou em que medida os argumentos de Fabian, naquele que é conhecido como o mais antigo documento japonês contra a doutrina cristã (HIBBARD 1962: 122), lhe poderão ter sido inculcados pelos mesmos Jesuítas que lhe ensinaram os fundamentos da nova religião? É para que consigamos compreender esse ponto essencial que iremos proceder a um sucinto estudo comparativo dos argumentos contra o Cristianismo patentes em ambas as obras, sendo que a do português, apesar de mais recente, é apresentada primeiro em virtude do seu contacto mais directo com esta religião.

Ambas as obras começam com uma pequena introdução, na qual os autores apresentam as circunstâncias que os levaram à escrita dos respectivos textos. Depois, enquanto a obra do português é mais directa, referindo sequencialmente várias dificuldades da doutrina cristã, a de Fabian alude repetidamente aos próprios argumentos dos cristãos, apenas para depois lhes juntar a sua própria refutação pessoal, em que frequentemente também recorre a argumentos provindos daquela que era a sua antiga religião, o budismo tal como este era praticado em terras do Japão.

\section{A Decepção Revelada, de Cristóvão Ferreira}

Desta forma, o primeiro argumento do português passa pelo problema da transmissão da mensagem divina ${ }^{5}$. Se Deus existe, se criou Adão, Eva e consequentemente toda a humanidade, como é possível que não tivesse proporcionado meios para que essa

\footnotetext{
4 De facto, nenhuma das fontes consultadas refere qualquer encontro entre eles.

5 Cristóvão Ferreira, A Decepção Revelada apud ELISON 1988: 297-299.
} 
mensagem fosse conhecida por todos os povos, em vez de somente pelos kirishitan? É uma questão intrigante, para a qual o autor não avança qualquer tipo de resposta, mas já não precisa de o fazer para atingir o seu novo objectivo - mais do que defender uma possível solução, através destas suas linhas pretende mostrar que existe um falha nos elementos mais basilares dos ensinamentos $\operatorname{cristãos}^{6}$, que, depois, logicamente leva ao seu passo seguinte.

Cristóvão Ferreira pergunta-se como poderiam apenas aqueles que são cristãos obter a salvação divina, a vida eterna no 'Paraiso'7. E continua - mesmo entre aqueles que já praticavam essa religião, como seria possível admitir a existência de 'predestinados' (que entrariam no Paraíso independentemente das suas acções) e 'reprobos' (a quem a salvação estava sempre negada)? Ou como justificar que aqueles que não foram baptizados - independentemente da sua idade - acabariam sempre no 'Inferno'? O autor liga estas múltiplas dificuldades ao pecado original de Adão, que comeu a 'maçan', mas como seria possível aceitar que Deus tivesse feito o Homem assim, capaz de cometer esse pecado único, apenas para depois o penalizar por exercer o seu livre-arbítrio? É essa liberdade humana que é vulgarmente utilizada para justificar a penalização divina. Mas se os kirishitan acreditavam que a possibilidade de fazer o bem só advinha da 'graça' divina, porque não a deu a todos os Homens como o fez a Maria, "livre de pecado"? São questões formidáveis, que nos conduzem - como a este autor - a diversas problemáticas importantes na Teologia cristã, mas que aqui teriam certamente o objectivo de suscitar questões nos fiéis, mostrando-lhes novamente que a mensagem veiculada nos catecismos não era tão simples como poderia fazer crer.

O terceiro argumento ${ }^{9}$ advém de uma confrontação do conteúdo dos dez mandamentos com as próprias acções dos kirishitan, de forma a demonstrar que essas regras nem sempre eram praticáveis ou praticadas pelos fiéis. De particular interesse é o sétimo mandamento - "não roubarás" - já que o autor menciona a autorização do "pappa' ${ }^{10}$ para uma divisão do mundo em duas metades, uma de Portugal e outra de Castela, nas quais esses dois reinos poderiam exercer o seu poder como bem entendessem ${ }^{11}$. Também associado a esse argumento surge uma breve explicação das funções e ocupações do clero, com o objectivo de mostrar que elementos como a

6 Como mostrado em PINTO DOS SANTOS 2011: 155-166, os catecismos disponíveis no Japão frequentemente começavam por este mesmo ponto.

7 Cristóvão Ferreira, A Decepção Revelada apud ELISON 1988: 299-302. Frise-se que o autor usa este mesmo termo, emprestado do português, como também o faz para os vários outros citados em seguida.

8 O fruto da famosa árvore nunca é identificado no texto bíblico, mas sabe-se que esta inferência nasceu do latim malum, que poderia não só significar "mal" como também "maçã".

9 Cristóvão Ferreira, A Decepção Revelada apud ELISON 1988: 302-309.

10 "O chefe da religião cristã, o representante de Jesus Cristo", cf. Cristóvão Ferreira, A Decepção Revelada apud ELISON 1988: 303.

11 Apesar de o autor não o nomear, trata-se de uma referência evidente ao Tratado de Tordesilhas. 
'excomunhão' ou a remissão de pecados eram usados somente para amealhar ouro e prata. Dada a sua grande importância, voltaremos ao (possível) roubo cristão mais à frente, mas não deixa de ser curiosa a referência à remissão humana dos pecados - que, recorde-se, não tem precedente na Bíblia - como ligada ao dinheiro. Certamente o autor estava familiarizado com as teses de Lutero, sabia que esta relação do perdão com o dinheiro representavam um entrave importante à Igreja Católica, e não se coíbe de a usar em favor da sua refutação.

Referindo-se depois à figura de Jesus Cristo, Cristóvão Ferreira conta a vida deste de uma forma muito sucinta, apontando-lhe alguns problemas - que não existem mais exemplos de um nascimento sem pai e mãe e que a própria Maria disse a Jesus "Este [i.e. José] é o teu pai" ${ }^{12}$; que Jesus foi circuncidado ${ }^{13}$ mesmo sem ter o pecado original ${ }^{14}$, ou seja, que o seu baptismo foi completamente desnecessário; que a presença dos Três Reis Magos em Belém teria sido impossível ${ }^{15}$; que a morte de Jesus se deveu ao facto de este ter "difamado pessoas de autoridade" 16 e procurado um trono ${ }^{17}$; que esta figura não ressuscitou nem ascendeu aos céus essas eram histórias "sem provas concretas (...), compostas pelos discípulos de Jesus Cristo"18. Seriam estes alguns dos argumentos contra os quais o autor teria aprendido a defender-se nos seus estudos em Coimbra e Macau (LEITÃO 1998: 293-294)? Dado que poderiam nascer de um contacto puramente laico com o texto bíblico, e que eram provavelmente referidos em diversas obras de controvérsias teológicas (cf. LEITÃO 2000: 133, CIESLIK 1974: 35-36), é muito provável que sim, razão pela qual o autor também saberia como evocá-los em favor da sua refutação.

Sobre os sacramentos, o autor português diz que quem recebe o 'baptismo' seria supostamente inspirado com a 'graça' divina, mas que a água não tem poder para afectar o 'spiritus' ${ }^{19}$; que a 'confissan' é inadmissível, os textos apenas mencionam uma 'contrição' ${ }^{20}$; que a transformação do pão em corpo e do vinho

12 Cristóvão Ferreira, A Decepção Revelada apud ELISON 1988: 309-310.

13 “A bênção da 'circuncisão' corresponde em significado ao 'baptismo'”, cf. Cristóvão Ferreira, $A$ Decepção Revelada apud ELISON 1988: 310.

14 Cristóvão Ferreira, A Decepção Revelada apud ELISON 1988: 310.

15 Cristóvão Ferreira, A Decepção Revelada apud ELISON 1988: 310-311.

16 Cristóvão Ferreira, A Decepção Revelada apud ELISON 1988: 312.

17 Cristóvão Ferreira, A Decepção Revelada apud ELISON 1988: 312-313.

18 Cristóvão Ferreira, A Decepção Revelada apud ELISON 1988: 313.

19 Cristóvão Ferreira, A Decepção Revelada apud ELISON 1988: 313-314.

20 Cristóvão Ferreira, A Decepção Revelada apud ELISON 1988: 314-315. 
em sangue é uma simples 'metaphora'"21. Todos estes se assemelham a argumentos que o autor também poderia ter aprendido na sua formação católica, mas isso é particularmente evidente em relação ao primeiro ponto, não tanto por se tratar de uma dificuldade que algum leigo poderia vir a levantar, mas por ser um argumento retirado da Filosofia e que o autor teria certamente aprendido no seu caminho curricular para a Teologia.

Finalmente, no seu "juízo geral"22, Cristóvão Ferreira aborda o problema da ressurreição. Segundo nos diz, o espaço físico seria insuficiente para que todos os Homens que já existiram reaparecessem no vale de 'Josaphat' ${ }^{23}$; dificilmente corpos em posições extremas - devorados, queimados ou reduzidos a cinzas poderiam voltar à sua forma original ${ }^{24}$. São problemas tão antigos como o próprio Cristianismo, com os quais o autor também provavelmente se tinha familiarizado durante a sua formação escolar, que aqui usa não tanto para defender uma ideia católica, mas com o objectivo aparente de demonstrar que existiam várias inconsistências lógicas na doutrina cristã.

Face a todos estes elementos podemos afirmar que $A$ Decepção Revelada apresenta, na sua generalidade, um conjunto de argumentos tão frontais quanto incisivos, com os quais um religioso cristão dificilmente não teria contacto durante a sua formação académica. Porém, essa singular presença de uma formação especializada, que bem conhecemos do currículo jesuítico da época, também nos leva a constatar um elemento curioso - os argumentos usados pelo autor são, no seu geral, bastante simples. Mais do que uma verdadeira refutação do Cristianismo, esta obra limita-se a apresentar uma breve referência a diversos problemas de ordem teológica, o que nos leva a outra questão fulcral - escrevendo estas suas linhas, estaria Cristóvão Ferreira a consumar uma rejeição pessoal do Cristianismo, ou ainda a tentar provar às autoridades japonesas a sua verdadeira apostasia (cf. LEITÃO 1998: 292, LEITÃO 2000: 132-133, PINTO DOS SANTOS 2011: 229-230)? A ausência de argumentos mais elaborados, bem como um possível arrependimento final (cf. CIESLIK 1974: 44-48), poderão levar-nos a apoiar a segunda hipótese, mas devemos igualmente ter em conta o facto de ele, alegadamente, ter cometido alguns actos contra os fiéis da sua antiga religião (cf. CIESLIK 1974: 23-27, LEITÃO 1998: 292, HIGASHIBABA 2001: 146). Considerando os dois lados da questão, acaba por ser difícil concluir-se algo em relação às razões que levaram tanto à sua apostasia como à escrita deste texto.

21 Cristóvão Ferreira, A Decepção Revelada apud ELISON 1988: 315.

22 A expressão é provavelmente a mesma usada pelo autor no original, como podemos depreender pelo facto de se encontrar seguida por uma breve explicação preservada na tradução de Elison - "'Juízo' means to inquire into things, 'Geral' means universal” (ELISON 1988: 316).

23 Cristóvão Ferreira, A Decepção Revelada apud ELISON 1988: 316-317.

24 Cristóvão Ferreira, A Decepção Revelada apud ELISON 1988: 316-317. 


\section{Deus Destruído, de Fabian Fukan}

Passando agora à obra de Fabian. O primeiro dos seus sete $\operatorname{passos}^{25}$ refere a ideia de que Deus (ou, mais precisamente, alguma divindade) criou o mundo, a que este autor não se opõe. Mas em seguida, numa discussão acerca das características de Deus, acrescenta que os Budas não foram apenas humanos, contrariando a opinião cristã e justificando a sua posição com argumentos filosóficos que lhe pareciam válidos. Para isso, menciona casos como os de Otomo Sorin de Bungo e Takayama Ukon (entre muitos outros), figuras caídas em desgraça depois de se terem convertido ao Cristianismo um argumento particularmente lógico para justificar uma possível vingança (ou perda de protecção) divina ${ }^{26}$. Seguem-se alguns argumentos que têm menos a ver com o cristianismo do que com a visão cristã do budismo, que depois continuam no segundo passo da obra ${ }^{27}$.

Já no terceiro passo é apresentada a doutrina de que Deus criou as criaturas a que chamamos 'anjo' antes da criação do Homem, sendo que um terço dos anjos se uniu a Lucifer e foi derrubado para o 'Inferno', passando a ser conhecido sob o nome de 'diabo'. O autor levanta o problema desta acção por parte de um Deus 'sapientissimus', que já saberia antecipadamente os efeitos da sua criação ${ }^{28}$. É um argumento que faz todo o sentido, que nos suscita uma primeira grande dificuldade da cultura cristã e que acaba por nos conduzir, naturalmente, ao argumento que o mesmo autor acabará por usar no passo seguinte.

O quarto passo apresenta a criação do Homem e a expulsão do 'Paraíso Terreal' por este ter comido a 'maçan'. Assim, o autor critica não só o facto de esta saída forçada ter ocorrido por causa de um mero fruto, mas também o problema de Deus saber, antecipadamente, que este evento ia ter lugar, mas mesmo assim nada ter feito contra isso $^{29}$. São, na sua essência, argumentos que poderiam nascer de uma leitura laica do conhecimento bíblico.

No quinto passo, o pecado de Adão e Eva é interpretado como imperdoável, por se tratar de um acto perpetrado contra o próprio Deus. A refutação é construída a partir do facto de Deus ter criado o Homem de forma imperfeita, mas mesmo assim apontar-lhe que nenhuma espécie de arrependimento seria suficiente para obter o perdão

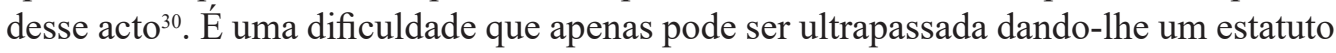

25 Conforme referido por HICHMEH 2015: 6, "Os sete passos apresentados por Fukan consistem nos alicerces doutrinários e espirituais que, segundo o autor, são transmitidos pelos Jesuítas para todos os iniciantes do cristianismo". Cf. BOXER 1967: 220.

26 Fabian Fukan, Deus Destruido apud ELISON 1988: 261-264.

27 Fabian Fukan, Deus Destruído apud ELISON 1988: 264-271.

28 Fabian Fukan, Deus Destruído apud ELISON 1988: 272-273.

29 Fabian Fukan, Deus Destruído apud ELISON 1988: 273-275.

30 Fabian Fukan, Deus Destruído apud ELISON 1988: 275-277. 
singular, que os pecados dos fiéis japoneses jamais poderiam vir a ter, mas que também mostra um Deus cristão que nem sempre é uma figura capaz de perdoar, contrariando a forma como a figura divina é vista no Novo Testamento.

O sexto passo é, essencialmente, um breve resumo da vida de Jesus Cristo, desde a concepção miraculosa de Maria (de quem é dito que se tratava de uma 'virgem', tal como José), até à ressurreição e ascensão aos céus ${ }^{31}$. Como fragilidades desta narrativa o autor aponta o longo período de tempo que demorou até Jesus Cristo vir à terra ${ }^{32}$; a estranheza da ausência de relações sexuais entre José e Maria ${ }^{33}$; o facto de Jesus se ter dito "Senhor do Céu e da Terra" e ter sido morto (o que, a Fabian, parece bem justificado) ${ }^{34}$. Como anteriormente, também é fácil compreender que estes são argumentos advindos de alguém que não poderia estar totalmente familiarizado com a teologia cristã. Podem ser facilmente reconhecidos como argumentos de alguma lógica, mas cuja resposta cristã se prende menos com a coerência e mais com a fé; desprovidos da segunda e num contexto em que se recorre exclusivamente à lógica, perdem grande parte do seu poder.

No sétimo passo são mencionados os dez 'mandamentos', juntamente como o sacramento do "baptismo' ${ }^{35}$. O autor considera essas dez regras semelhantes às da sua religião, mas aborda apenas o primeiro de uma forma mais alongada, já que vê nele uma enorme violação dos deveres que os japoneses tinham para com os seus superiores "lealdade e recompensa" no caso de um servo e um mestre ou "piedade filial e afecto parental" no caso pai e um filho ${ }^{36}$, entre outros exemplos possíveis. Por isso, Fabian sente a necessidade de fazer uma pequena apologia da sua cultura e dos seus costumes, levando à ideia de que este mandamento era usado para uma tentativa da conquista do Japão - bem como de outras terras, como 'Luzon' ou a 'Nova Hispania' - por parte dos Bateren $^{37}$, nome dado frequentemente aos padres jesuítas. São aqui claramente visíveis as distinções culturais entre o Ocidente Europeu e o Japão, mas voltaremos ao argumento do (possível) roubo mais à frente.

Após estes sete passos tem lugar uma sequência de perguntas e respostas, em que Fabian vai esclarecendo alguns pontos que lhe parecem importantes. Em relação ao dia-a-dia dos Bateren, é referida a 'missa' e a 'ostia', considerando o autor que a transmutação do pão e do vinho "não é credível"38. Refere também que as várias ordens religiosas cristãs costumam ter muitos conflitos entre si (cf. Boxer 1967: 154ff),

31 Fabian Fukan, Deus Destruído apud ELISON 1988: 278-279.

32 Fabian Fukan, Deus Destruído apud ELISON 1988: 279.

33 Fabian Fukan, Deus Destruído apud ELISON 1988: 279.

34 Fabian Fukan, Deus Destruído apud ELISON 1988: 280.

35 Fabian Fukan, Deus Destruído apud ELISON 1988: 280-281.

36 Fabian Fukan, Deus Destruído apud ELISON 1988: 282.

37 Fabian Fukan, Deus Destruído apud ELISON 1988: 283-284.

38 Fabian Fukan, Deus Destruído apud ELISON 1988: 286. 
mostrando-nos que a fé dos adeptos desta religião não era una. Na questão seguinte, o autor menciona que os cristãos "nem consideram os japoneses como humanos" 39 , e que diziam que não podiam deixar os japoneses ser Bateren já que estes, em último caso, defenderiam somente os interesses do seu próprio país ${ }^{40}$. Na terceira questão, os paroquianos mais ricos são vistos como superiores aos pobres e é revelado que, na opinião deste autor, os trabalhos de caridade dos cristãos eram feitos "somente pelo prestígio e para obterem lucro"41. Estes Bateren são depois, de uma forma talvez até um pouco jocosa, vistos como "Padres", no sentido latino da palavra, já que em algumas localidades fora do Japão até tinham mulher e filhos ${ }^{42}$. O acto da 'confissam' é visto como um simples remédio para todas as ofensas, por piores que tenham sido ${ }^{43}$. A ideia dos milagres como potencialmente reais é totalmente descartada ${ }^{44}$. Finalmente, a obra termina com uma referência pessoal à fuga de Fabian, em que o próprio autor se diz perseguido pelos cristãos devido ao seu estatuto de apóstata ${ }^{45}$.

Através dos argumentos patentes nesta segunda obra podemos ver no Deus Destruído de Fabian Fukan uma refutação do cristianismo tal como este era apresentado em terras do Japão. Sabemos que conhecia os catecismos pelo facto de ter estudado em colégios jesuítas, mas também porque os menciona numa obra em favor da nova religião ${ }^{46}$ escrita alguns anos antes ${ }^{47}$, justificando-se assim os inegáveis paralelismos temáticos que estes apresentam em relação aos conteúdos das duas obras da autoria deste mesmo autor (HUMBERTCLAUDE 1938: 521-522, cf. PINTO DOS SANTOS 2011: 155-166). De facto, essa correspondência de argumentos similares, usados em primeiro lugar para apoiar e posteriormente para refutar uma mesma religião, está perfeitamente sintetizada nas palavras de um estudioso dos nossos dias - "O cristianismo do Diálogo Myotei é, para o Fukan cristão, compatível e, ainda, recomendável a todo o Japão; em Deus Destruído, em contrapartida, é apresentado como uma doutrina perniciosa e ameaçadora aos costumes e tradições japoneses" (HICHMEH 2015: 8-9).

Ademais, se o autor também recorre a alguns argumentos do seu budismo nipónico e a episódios particulares que tiveram lugar no Japão, fá-lo com o objectivo de ter uma

39 Fabian Fukan, Deus Destruído apud ELISON 1988: 286.

40 Fabian Fukan, Deus Destruído apud ELISON 1988: 286-287.

41 Fabian Fukan, Deus Destruído apud ELISON 1988: 287.

42 Fabian Fukan, Deus Destruído apud ELISON 1988: 287.

43 Fabian Fukan, Deus Destruído apud ELISON 1988: 288.

44 Fabian Fukan, Deus Destruído apud ELISON 1988: 288-290.

45 Fabian Fukan, Deus Destruído apud ELISON 1988: 290.

46 HUMBERTCLAUDE 1938: 519, Fabian Fukan, Diálogo Myotei apud HUMBERTCLAUDE 1939: 244.

47 De acordo com HUMBERTCLAUDE 1941: 617, o Diálogo Myotei foi escrito em 1605, enquanto que o Deus Destruído data de 1620, onze anos depois do autor deixar os Jesuítas. 
base cultural de onde partir, uma pedra basilar que os Jesuítas não tinham e que pareciam insistir em descartar como pouco importante - recorde-se que, nas palavras deste autor, esses religiosos "nem consideram os japoneses como humanos" de tratamentos que levou o autor a abandonar o cristianismo ${ }^{49}$ ? É possível que sim, dada a sua referência directa ao facto dos japoneses serem frequentemente impedidos de se tornarem Bateren $^{50}$, mas de um ponto de vista neutro devemos igualmente ter em conta que Fabian parecia ter um conhecimento incompleto de alguns fundamentos essenciais da religião cristã (cf. HIBBARD 1962: 128, HIGASHIBABA 2001: 85), o que até pode justificar uma relutância jesuítica em lhe atribuir um papel religioso de maior relevância. Porém, qualquer que tenha sido a razão para a sua apostasia, devemos frisar que esta figura foi considerada como um dos mais importantes representantes do cristianismo no Japão, aparecendo como opositor ao budismo em obras como Kirishitan Monogatari.

\section{Comparação das duas obras}

Finda esta breve apresentação das duas obras devemos agora ter em conta os seus elementos comuns. É fácil constatar que a estrutura geral de ambas é muito semelhante, o que se poderá justificar tendo em conta o conteúdo dos diversos catecismos então disponíveis no Japão. Para dar um primeiro exemplo, ambos os autores referem o problema da expulsão do Paraíso; se o Deus cristão perdoa aqueles que se arrependem, como é possível a existência de um "pecado original" comum a toda a humanidade? Por muitos que possam ser os argumentos apresentados para a resolução deste problema em particular, de um ponto de vista lógico ele representa uma inconsistência muito difícil de ser resolvida fora do reino exclusivo da fé, razão pela qual as obras doutrinárias mencionavam frequentemente esse ponto (cf. PINTO DOS SANTOS 2011: 155-166), que depois continuará a ser referido por autores posteriores (cf. NAKAGAWA 1992: 35-36).

Ambos dissertam sobre os dez mandamentos e os sacramentos, apresentando uma inconsistência entre o que a doutrina dizia e o que era realmente praticado pelos cristãos. Se bem que de uma forma ligeiramente diferente, ambos os autores usam este ponto para apresentar o cristianismo como uma forma dissimulada de colocar novas terras sob o domínio de Deus e do papa. Este é um problema constantemente associado aos cristãos na literatura anti-cristã japonesa, que pela sua fama e importância também é repetido por autores ulteriores (Cf. NAKAGAWA 1992: 39). Não sabemos se esta terá sido uma ideia provinda da "Doação de Bartolomeu" (ELISON 1988: 85-106), em que Nagasaki foi essencialmente cedida aos Jesuítas (HALL 1997: 329); da conquista efectiva de outras terras (recorde-se que Fabian demonstra conhecimento de isso já ter acontecido nos casos de 'Luzon' e da 'Nova Hispania'); do conteúdo de obras

48 Fabian Fukan, Deus Destruído apud ELISON 1988: 286.

49 Fabian Fukan, Deus Destruido apud ELISON 1988: 154-159, 163-164.

50 Fabian Fukan, Deus Destruido apud ELISON 1988: 286-287. 
como Kirishitan Kanagaki (ELISONAS 2007: 48ff), na qual aparecia divulgado um suposto plano cristão para a conquista mundial; ou de um conflito ideológico entre as duas culturas, mas é indiscutível que esse medo de uma conquista europeia parece ter existido na cultura japonesa do século XVII ${ }^{51}$, com ambos os autores a advertirem essa possibilidade.

Também referem alguns problemas relativos à vida de Jesus Cristo. A sua semelhança com outras figuras de carácter religioso já era bem conhecida na Antiguidade $^{52}$, mas para estes dois autores o grande problema parece advir do carácter único de Jesus, uma espécie de homem cuja vida se encontrava pejada de elementos que, a serem atribuídos a outras figuras, dificilmente seriam vistos como verdadeiros. Se, como já foi visto, Maria dizia explicitamente que José era o pai de Jesus, como seria possível dar-lhe uma paternidade divina? Como aceitar a ausência perpétua de relações sexuais entre José e Maria? Como compreender uma crucificação injustificada, face a algumas afirmações do próprio Jesus? Sem a necessária pedra basilar da fé, elementos como estes seriam difíceis de aceitar, tornando-se puramente absurdos. É por essa mesma razão que ambos os autores recorrem a eles na sua necessidade de mostrar alguns dos problemas do cristianismo.

\section{Conclusões}

Fundamentalmente, Cristóvão Ferreira e Fabian Fukan fazem uma oposição ao cristianismo do seu século com base em argumentos derivados da sua experiência pessoal com a mesma religião. Têm diversos pontos em comum, certamente derivados da sua formação e do seu contacto com diferentes faces das mesmas crenças, mas também fazem uma oposição a esta religião que não pode nem deve ser separada do contexto e condições em que foi realizada. Parece-nos justo afirmar que mais do que refutarem a religião cristã, os dois autores focam-se na apófase de uma versão muito particular do cristianismo, tal como este foi levado para o Japão, apresentado e representado num período de tempo muito concreto.

\section{Referências Bibliográficas}

BOXER, Charles. The Christian Century in Japan, 1549-1650. Berkeley: University of California Press, 1967.

CIESLIK, Hubert. The case of Christovão Ferreira. Monumenta Nipponica, Tokyo, Vol. 29, N $^{\circ}$ 1, pp. 1-54, Primavera 1974.

ELISON, George. Deus Destroyed: The Image of Christianity in Early Modern Japan. Cambridge, Mass.: Harvard University Press, 1988.

51 Para um exemplo curioso desta possibilidade nas declarações de apóstatas cristãos, ver HIGASHIBABA 2001: 146.

52 Recorde-se que ele era então comparado com figuras como Orfeu, Baco e Apolónio de Tiana. 
ELISONAS, Jurgis. Journey to the West. Japanese Journal of Religious Studies, Nagoya, Vol. 34, No 1, pp. 27-66, 2007.

HALL, John, MCCLAIN, James. The Cambridge History of Japan: Volume 4. Cambridge: Cambridge University Press, 1997.

HIBBARD, Esther, HIRAISHI, Yoshimori. Refutation of Deus by Fabian. Contemporary Religions in Japan, Nagoya, Vol. 3, Nº 2 , pp. 122-150, Junho 1962.

HICHMEH, Yuri. O trauma católico no Japão do século XVII: a apostasia de Fabian Fukan e a legitimação à perseguição nipônica ao cristianismo. XXVIII Simpósio Nacional de História, Florianópolis, 2015. Consultado online: http:/www.snh2015.anpuh.org/resources/ anais/39/1428337916_ARQUIVO_ANPUH2015Fukantexto.pdf [acesso 11-8-2018].

HIGASHIBABA, Ikuo. Christianity in Early Modern Japan: Kirishitan Belief and Practice. Leiden: Brill, 2001.

HUMBERTCLAUDE, Pierre. Myôtei Mondô: Une apologétique chrétienne japonaise de 1605. Monumenta Nipponica, Tokyo, Vol. 1, Nº 2, pp. 515-548, Julho 1938.

Myôtei Mondô: Une apologétique chrétienne japonaise de 1605. Monumenta Nipponica, Tokyo, Vol. 2, No 1, pp. 237-267, Janeiro 1939.

Notes complémentaires sur la biographie de l'ex-Frére Jésuite Fabien Fucan. Monumenta Nipponica, Tokyo, Vol. 4, No 2, pp. 617-621, Julho 1941.

LEITÃO, Henrique, PINTO DOS SANTOS, José. O Kenkon Bensetsu e a recepção da cosmologia ocidental no Japão do séc. XVII. Revista Portuguesa de Filosofia, Braga, T. 54, Fasc. 2, pp. 285-318, 1998.

LEITÃO, Henrique. Reseña de 'La Supercherie Dévoilée. Une Réfutation du Catholocisme au Japon au XVIIe Siécle' de Jacques Proust. Bulletin of Portuguese / Japanese Studies, Lisboa, Año/Vol 1, pp. 131-134, Dezembro 2000.

NAKAGAWA, Hisayasu. La réfutation du christianisme par Hakuseki Arai. 仏文研究, Kyoto, $\mathrm{No}^{\circ}$ 23, pp. 31-43, Setembro 1992.

PINTO DOS SANTOS, José. A study in cross-cultural transmission of natural philosophy: the Kenkon Bensetsu. Dissertação de Doutoramento. Lisboa: Universidade Nova, 2011. 